\title{
The Application of Digitalization in Enterprises on the Basis of Multiple Criteria Selection Design
}

\author{
Yuliia Vorzhakova', Kateryna Boiarynova²
}

Submitted: 13.06.20. Accepted: 28.09.20

\section{Abstract}

Purpose: The increasing role of digitalization in the operation of enterprises actualizes the implementation of the basic methods of proper digitalization processes. The selection of an appropriate method to introduce digitalization is crucial, as it affects the optimization level of the business processes.

Methodology: Specific multicriteria selection method includes five steps to identify these approaches, considering the relative error for each approach, as it affects the outcome with the performance indicator of business process digitalization. The strongest criterion value is used to identify the optimal approach. The evaluation of the methods showed that the performance of the logistic, administrative, and innovative methods is not worse than the Pareto principle.

Findings: Introducing digitalization in the administrative method has the biggest impact. The chosen method showed that Human Resources processes require modification to reduce costs. A mechanism to digitalize the personnel management processes using artificial intelligence was developed.

Implications: The results of multivariate multicriteria analysis show that the implementation of artificial intelligence minimizes human factors and optimizes time and costs.

Originality: The main contribution is the development of the method for the selection of an appropriate digitalization approach, which encompasses an implementation mechanism that can be adapted to enterprises' needs.

Keywords: digitalization, approaches, mechanism, artificial intelligence, business processes.

JEL: M12, 015

\footnotetext{
1 National Technical University of Ukraine - Igor Sikorsky Kyiv Polytechnic Institute, Peremohy Ave, 37, Kyiv, Ukraine, 03056 e-mail: Julija. vorzhakova@gmail.com, https://orcid.org/0000-0002-0521-3318.

2 National Technical University of Ukraine - Igor Sikorsky Kyiv Polytechnic Institute, Peremohy Ave, 37, Kyiv, Ukraine, 03056, e-mail: boyarinovaea@ukr.net, https://orcid.org/0000-0001-5879-2213.
} 


\section{Introduction}

The digital era, dubbed the Fourth Industrial Revolution, has led to a fundamental reboot of all spheres of social life, especially on the principles of digitalization. The advent of Industry 4.0 means the widespread adoption of digital technologies in enterprise, industry, and government management system. This is a crucial milestone for Ukraine, as the "Strategy for the Development of the Digital Economy of Ukraine" - approved by the Cabinet of Ministers of Ukraine in early 2018 - and its corresponding plan of measures for the implementation of this initiative has led to the development of digitalization in Ukraine at all levels. At the enterprise level, digitalization extends to all business processes, changing traditional methods to a virtual environment that adds to our reality and changes business mechanisms. In particular, the digitalization of personnel management processes is complemented by using artificial intelligence, e.g. the introduction of chatbots allows companies to minimize human factors to optimize time and costs.

\section{Literature Review}

The topic of digital economy has been researched by many scientists in Ukraine and abroad. One of the first publications on the topic of digitalization, in which the term 'digitalization' was introduced, describes the Fourth Industrial Revolution as a confluence of technologies that blur boundaries between the physical, digital, and biological spheres (Schwab, 2016)

Kraus et al. (2018) note that digital economy is individually tailored to the consumer and consider their comprehensive information use as the driving force for the implementation of digitalization, taking into account specific features of a particular consumer at a particular place alongside with the global use of digital business transformation technologies of real business processes.

Problems associated with digitalization in enterprises have recently become one of the most researched topics among the Ukrainian scientists (Guseva, 2018; Gribinenko, 2018; Yurchak, 2019; Gavrilenko, 2019; Lazebnik, 2018). The economists note that the main point for improving business process management in enterprises is caused by an increasing need to introduce digital tools in modern business operations. The discrepancies in scientific views are caused by the lack of a paradigm that would allow us to identify digitalization within the structure of human values and include it in general organization principles. Defining the metrics to measure the economic and social impact of the transformation of personnel management system in an enterprise 
due to the newly introduced digitalization practices is an important issue (Borysyak, 2018), also emphasized by Merkevicius et al. (2015). When studying virtual organization as a form of collaboration of combined work resources from different geographical places for the realization of common goals fulfilled by personnel in accordance with existing competence, scholars pay attention to the restructuring of personnel management system with the use of information technologies to combine intellectual and geographical heterogeneity of manpower (Merkevicius, 2015).

Rohrbeck et al. (2015), Shalmo et al. (2017), Rachinger et al. (2018), and Bouwman et al. (2018) emphasize the need for such a research and identify the predominant role of digital processes and decision-making through Industry 4.0, Big Data or Artificial Intelligence. The development of a scientific perspective on the introduction of artificial intelligence into the human resource management process is also discussed by Eder and Buck (2018). These two authors note that the knowledge of cyber-physical systems or the analytical knowledge of data processing becomes necessary and requires changes in workforce skills, which leads to a change in centrism (Eder and Buck, 2018).

Kolot (2019) describes the role and significance of a transformation in all spheres of human life, especially its importance in the human resource management in Industry 4.0, stating the necessity to use labor resources in the coordinates generated by the Fourth Industrial Revolution; specifically, what acquires new features and content is the fundamentally new type of labor process, consisting of objects, means of labor, and employees.

The adaptation of personnel management processes to Ukrainian businesses is considered by scientists from the standpoint of creating recruiting bots, which eliminates the human factor; not to mention staff relocation, coworking, and the compatibility of artificial intelligence (bots, chatbots) and humans (Borysyak, 2018; Batrakova, 2018). The existence of different views on the introduction of artificial intelligence into HRM processes drives the development of theoretical and social foundations of digitalization in HRM processes, as the basis for the transition of HRM to Industry 4.0 systems.

\section{Data and Method}

This article describes a multivariate multicriteria method of choosing the optimal approach for the implementation of digitalization in enterprises. Enterprises of the printing industry are taken as an example. This methodological approach is based on multivariate synthesis with a sequential selection of the optimal method of structural 
and parametric construction, which ensures the highest efficiency of the acceptable system (Kandirin, 2008). The methodology incorporates the definition of main characteristics for the implementation of the digitalization processes in enterprises. These characteristics are considered as a set of impact factors $\{\mathrm{IF}\}$. Depending on their functional purpose, the priority of the IF is established alongside the tasks to form criteria and establish algorithms and programs for automated choice.

Systematic approaches to digitalization implementation in enterprises are formed by several actions:

- creating the product value of processes (logistic, marketing);

- performing auxiliary works (innovative, technological);

- managing information and personnel (production, management);

- forming a company's development plan (competitive, holding).

The choice of approach for a suitable digitalization method for a specific enterprise depends on the ability to ensure the enterprise's efficiency, e.g. by meeting consumer needs, ensuring a high level of competitiveness in comparison with other businesses, improving the efficiency of the enterprise.

In order to select an acceptable approach, a comparison is made between the most prevalent approaches, which are then ordered using the values of their main characteristics. The units of these characteristics are $v,(m / I), \delta, C$, in which $v$ is the speed of coverage of new technologies in business expressed in new processes per year; $m / I$ is the specific method expressed as innovations/measures of the approach; $\delta$ is the relative error of the approach that affects performance; $t$ is time span expressed in days.

Each version of the system is described by a set of general characteristics that are conditionally divided into impact factors $\{\mathrm{IF}\}$, limitations $\{\mathrm{L}\}$, and condition $\{\mathrm{C}\}$, which is necessary for finding a suitable solution for a specific task. The analysis of the main predefined characteristic for all approaches allows us to determine the range for their values, which in turn are used for the selection of the most suitable approach and the specification of impact factors.

By using Common Approach Characteristics (CAC), the array of all known approaches is reduced to a defined region, which consists of $\{\mathrm{C}\}$ and $\{\mathrm{L}\}$ sets. Therefore, it becomes possible to select not worse or preferably even better options according to the optimal acceptable results (OAR) criterion from a defined $\{\mathrm{IF}\}$ set. 
The specific multicriteria selection (SMS) method is a complex multidimensional combinatorial problem that should be solved stepwise. The first step is to form the target set $\{\mathrm{IF}\}$ and select the specific weight criterion. In each specific task, some characteristics must be attributed to $\{\mathrm{IF}\}$ and some to $\{\mathrm{C}, \mathrm{L}\}$. Unconditional and conditional preference criteria can be used for comparative analysis and choice of approach (Table 1). The selection of preference criteria is based on the manager's level of awareness of the problems. At a low awareness level, it is advisable to use unconditional $\pi$ or the S-criteria of preference and, at the high awareness level, conditional L-criteria or integral $\Sigma$, P convolutions (Kandirin, 2008).

Based on the ontological (essential) prerequisites for the problem of choosing the structure of the approach - and considering the main characteristics - the following conditional subdivision of external characteristics is introduced:

- conditions, $\alpha$, are compared using the relation $\mathrm{R}_{\mathrm{y}}=\{=, \neq, \approx\}$, in which $\alpha$ is a conditional range for the specific approach selection. Each approach has a set range in which the implementation of the strategic plan (SP) is required.

- limitations are described by the relation $\mathrm{R}_{\mathrm{O}}=\{>,<, \geq, \leq\}$. These include $\mathrm{v}_{\max } \geq \mathrm{v}_{\text {need }}$ as the maximum expansion speed of new technologies into businesses process technologies, ensured by the approach that should be greater than or equal to that required by SP.

- $\mathrm{m} / \mathrm{I} \leq[\mathrm{m} / \mathrm{I}]_{\mathrm{TZ}}$ is the proportion of innovations in the approach that should not exceed the requirement of the strategic plan SP.

- the impact factor for a chosen method is selected by defining two external characteristics that have a significant impact on the approach, whose values should be minimized. For example, the chosen approach should provide a minimum guidance error $\delta$ at minimal cost $C \downarrow$.

In the second step, the task of selecting the type of approach to develop a method that provides the expansion of new technologies in business processes between two time points, $\mathrm{t} 1=0$ and $\mathrm{t} 2=360$ days, with the speed of new business process technologies expansion should be no less than required by the $\mathrm{SP}\left[v_{\text {need }}\right]_{\mathrm{TZ}}=5$, while the proportion of innovation should not exceed what is permissible $[\mathrm{m} / I]_{\mathrm{TZ}}$. The chosen error $\delta$ and costs $C$ in IF quality require minimization. At this point, the output is considered by characteristics in the increasing linear order. The design decisions are denoted by $\omega_{i}$, in which $\Omega=\left\{\omega_{i}\right\}$ are all possible solutions.

In the third step, the formalized choice of the approach based on raw data is presented (Table 1) using the unconditional Pareto criterion due to the factor of sets $\mathrm{F}_{\Omega}\left(k_{1}\right)$ and 
$\mathrm{F}_{\Omega}\left(k_{2}\right)$ for linear orders on PV. For this purpose, a chain of lexicography for $\delta=k_{1} \downarrow$ and $C=k_{2} \downarrow$

$$
\begin{aligned}
& L\left(\Omega / k_{1}\left(\omega_{i}\right)\right)=<\omega_{2}, \omega_{1}, \omega_{3}, \omega_{6},\left\{\omega_{5}, \omega_{8}\right\}, \omega_{4}, \omega_{7}>, \forall i=\{1,8\} \\
& L\left(\Omega / k_{2}\left(\omega_{i}\right)\right)=<\omega_{6}, \omega_{7}, \omega_{5}, \omega_{8},\left\{\omega_{4}, \omega_{3}\right\}, \omega_{1}, \omega_{2}>, \forall i=\{1,8\}
\end{aligned}
$$

and the corresponding relational tables for the transitive factors of the sets $\mathrm{F}_{\Omega}^{\mathrm{T}}\left(k_{1}\right)$ and $\mathrm{F}_{\Omega}^{\mathrm{T}}\left(k_{2}\right)$ (Tables 2 and 3) were formed as a set of spatial alternatives $\left\{O_{\mathrm{i}}\left(\omega_{\mathrm{i}}\right) k_{1}\right\}$ and $\left\{O_{\mathrm{i}}\left(\omega_{\mathrm{i}}\right) k_{2}\right\}$.

\section{Table 1. Possible selection criteria}

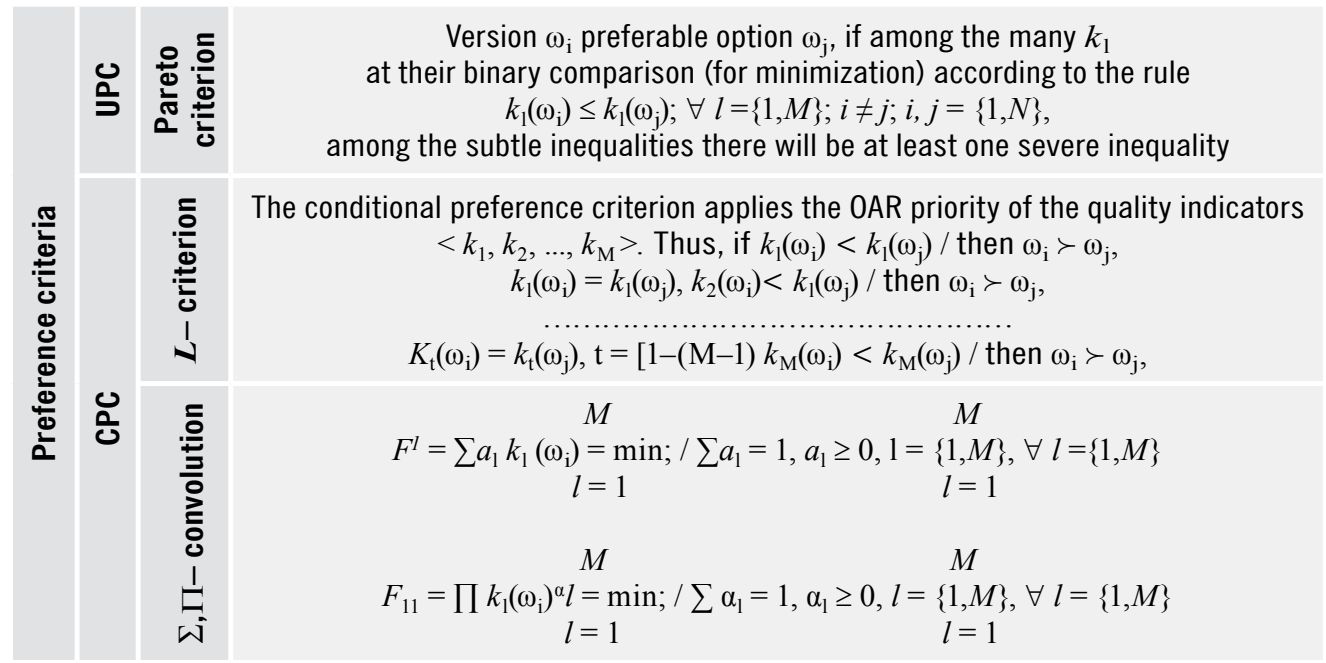

Source: own elaboration based on Kandirin (2008).

Full partial order on $\Omega$ as the majority factor for the Pareto criterion of arbitrary dimension $\pi\left(\Omega\left\{k_{1}, \ldots k_{l}\right\}\right)$ is determined by the intersection of the neighboring $O_{i}\left(\omega_{i}\right)_{k l}$ items $\omega_{i}$ factor of sets $\mathrm{F}^{\mathrm{T}}\left(\Omega / k_{1}\right), \ldots, \ldots, \mathrm{F}\left(\Omega / k_{M}\right)$ for lower orders $\forall l=\{1, M\}$ (Kandirin, 2004):

$$
\begin{gathered}
O_{i}\left(\Omega / k_{1}\right) \cap \ldots \cap O_{i}\left(\Omega / k_{l}\right)=\left\{\left\{\omega_{j}:\left[k_{1}\left(\omega_{j}\right) \leq k_{1}\left(\omega_{i}\right)\right]\right\} \wedge\left\{\omega_{p}:\left[k_{2}\left(\omega_{p}\right) \leq k_{2}\left(\omega_{i}\right)\right]\right\} \wedge \ldots\right. \\
\left.\ldots \wedge\left\{\omega_{q}:\left[k_{l}\left(\omega_{q}\right) \leq k_{l}\left(\omega_{i}\right)\right]\right\}, \omega_{i, j, p, q} \in \Omega\right\} .
\end{gathered}
$$


Or more compact for $l \in M$ received as

$$
\begin{gathered}
\bigcap O_{i}\left(\Omega / k_{l}\right)=\bigcap\left\{\omega_{j}:\left[k_{l}\left(\omega_{j}\right) \leq k_{l}\left(\omega_{i}\right)\right] \wedge\left[k_{l}\left(\omega_{s}\right)<k_{l}\left(\omega_{i}\right)\right], \forall l \in M, \omega_{j, i, s} \subseteq \Omega\right\} . \\
l=1, \omega i, j_{j} \in \Omega \quad l=1, \omega i, j_{l,} \in \Omega
\end{gathered}
$$

In the fourth step, we consider the solution to the problem of choosing acceptable by the $\pi$-criterion variants of the associative ordering approaches when describing the factors of sets by associative matrices. This is appropriate when using automated selection systems that work optimally on binary data and Boolean algebra. For this purpose, as follows from expression (1), it is necessary to realize the intersection factor of the sets of all assigned OAR, the impact indicators. The section of the columns is considered $\mathrm{C}_{l 1}$ and $\mathrm{C}_{l 2}$ arbitrary associative matrices (AM) $A_{l 1} \cap A_{l 2}$ factor of sets.

$$
C_{l 1} \cap C_{2}=\left(\begin{array}{l}
B_{1} \\
B_{2} \\
\cdots \\
B_{l}
\end{array}\right)_{11} \cap\left(\begin{array}{l}
B_{1} \\
B_{2} \\
\cdots \\
B_{1}
\end{array}\right)_{12}=\left(\begin{array}{l}
G_{1} \\
G_{2} \\
\cdots \\
G_{1}
\end{array}\right),
$$

in which $\mathrm{G}_{i}=\left(B_{i}\right)_{l 1} \cap\left(B_{i}\right)_{l}, i=\{1, N\}$.

The result will be the same for all columns of associative matrices $A_{l 1}, A_{l 2}$

$$
C_{l l k} \cap C_{l 2 k}=\left(\begin{array}{l}
B_{1 k} \\
B_{2 k} \\
\cdots \\
B_{u k}
\end{array}\right)_{\| l} \cap\left(\begin{array}{l}
B_{1 k} \\
B_{2 k} \\
\cdots \\
B_{u k}
\end{array}\right)_{12}=\left(\begin{array}{l}
G_{1 k} \\
G_{2 k} \\
\cdots \\
G_{u}
\end{array}\right),
$$

in which $G_{i k}=\left(B_{i k}\right)_{l 1} \cap\left(B_{i k}\right)_{l 2}, i=\{1, N\}, k=\{1, N\}$.

For all associative matrices, the factor from the set of an arbitrary dimension impact indicators is generalized, which gives the expression that determines the resultant associative matrix (RAM) $A_{\text {res, 1,2..,m }}$ :

$$
\boldsymbol{G}_{i k}=\boldsymbol{B}_{i k}^{1} \cap \boldsymbol{B}^{2}{ }_{i k} \cap \ldots \cap \boldsymbol{B}^{m}{ }_{i k}, i, k=\{1, N\}
$$


The occurrence of the variant in the corresponding space is identified by "1" in this cell, the absence - "0", meaning that if the variant occurs in the $i$-th space, the element of the associative matrix $B_{i, j}$ is $1\left(B_{i, j}=1\right)$, otherwise $B_{i, j}$ is $0\left(B_{i, j}=0\right)$, if the occurrence is not included. In the associative form, the space consists of the columns of the associative matrix and, subsequently, the matrix of the resultant set of factors for the selected impact indicators which is formed as a sequential element intersection of the columns of the associative matrices, is a factor of smaller dimensions

$$
G i, j=\left\{\begin{array}{l}
1, \text { if } B_{i, j}^{1} \Lambda B_{i, j}^{2} \Lambda \ldots B_{i, j}^{1} \ldots \Lambda B_{i, j}^{M}=1 \\
0, \text { if } B_{i, j}^{1} \Lambda B_{i, j}^{2} \Lambda \ldots B_{i, j}^{1} \ldots \Lambda B_{i, j}^{M}=0
\end{array}\right\}, l=\{1, M\}
$$

In the fifth step, the relational tables for the factors $\mathrm{F}^{\mathrm{T}}\left(\Omega / k_{1}\right)$ and $\mathrm{F}^{\mathrm{T}}\left(\Omega / k_{2}\right)$ are generated (Tables 2 and 3) in the form of corresponding associative matrices and their intersection by expression (2).

\section{Table 2. Plural factor $\mathbf{F}^{\mathrm{T}} \Omega\left(\boldsymbol{k}_{\mathbf{1}}\right)$}

\begin{tabular}{|c|c|}
\hline & $\mathbf{F}^{\mathrm{T}} \Omega\left(\boldsymbol{k}_{\mathbf{1}}\right)$ \\
\hline$\omega_{\mathbf{i}}$ & $\boldsymbol{O}_{\boldsymbol{i}}\left(\boldsymbol{\omega}_{i}\right) \boldsymbol{k}_{\mathbf{1}}$ \\
\hline$\omega_{1}$ & $\omega_{1} ; \omega_{3} ; \omega_{8} ; \omega_{6} ; \omega_{2}$ \\
\hline$\omega_{2}$ & $\Omega_{2}$ \\
\hline$\omega_{3}$ & $\omega_{5} ; \omega_{1} ; \omega_{3} ; \omega_{8} ; \omega_{6} ; \omega_{2}$ \\
\hline$\omega_{4}$ & $\omega_{1} ; \omega_{2}$ \\
\hline$\omega_{5}$ & $\omega_{5} ; \omega_{1} ; \omega_{4} ; \omega_{3} ; \omega_{8} ; \omega_{6} ; \omega_{2}$ \\
\hline$\omega_{6}$ & $\omega_{5} ; \omega_{1} ; \omega_{3} ; \omega_{6} ; \omega_{2}$ \\
\hline$\omega_{7}$ & $\omega_{1} ; \omega_{3} ; \omega_{2}$ \\
\hline$\omega_{8}$ & $\varnothing$ \\
\hline
\end{tabular}

Table 3. Plural factor $\mathbf{F}^{\mathrm{T}} \Omega\left(\boldsymbol{k}_{\mathbf{2}}\right)$

\begin{tabular}{cc}
\hline & $\mathbf{F}^{\mathrm{T}} \Omega\left(\boldsymbol{k}_{2}\right)$ \\
\hline$\omega_{\mathbf{i}}$ & $\boldsymbol{O}_{\boldsymbol{i}}\left(\boldsymbol{\omega}_{\boldsymbol{i}}\right) \boldsymbol{k}_{2}$ \\
\hline$\omega_{1}$ & $\omega_{7} ; \omega_{8} ; \omega_{6} ;$ \\
\hline$\omega_{2}$ & $\omega_{5} ; \omega_{4} ; \omega_{3} ; \omega_{7} ; \omega_{8} ; \omega_{6} ; \omega_{2}$ \\
\hline$\omega_{3}$ & $\omega_{5} ; \omega_{3} ; \omega_{7} ; \omega_{8} ; \omega_{6}$ \\
\hline$\omega_{4}$ & $\omega_{5} ; \omega_{4} ; \omega_{7} ; \omega_{8} ; \omega_{6}$ \\
\hline$\omega_{5}$ & $\omega_{8}$ \\
\hline$\omega_{6}$ & $\varnothing$ \\
\hline$\omega_{7}$ & $\omega_{7} ; \omega_{8}$ \\
\hline$\omega_{8}$ & $\omega_{5} ; \omega_{4} ; \omega_{3} ; \omega_{7} ; \omega_{8} ; \omega_{6}$
\end{tabular}

Source: own elaboration based on Kandirin (2004, 2008).

In the sixth step, the resulting associative matrices (AM) for the factor set was submitted as $\mathrm{F}^{\mathrm{T}}\left(\Omega /\left\{k_{1}, k_{2}\right\}\right)$ on the basis of expression (2). Therefore, the alternative $i$ is included in the set of worse solutions, if its space is an empty set, meaning that condition (3) is satisfied for the elements

$$
\bigcup_{k=1}^{N} G_{k i}=0
$$


for a column AMi in the $i$-th space $\operatorname{Oi}(\omega i /\{k 1, . ., k M\})$ of the alternative $\omega i$.

This transitive graph $\mathrm{G}^{\mathrm{T}}\left(\Omega, \mathrm{U}_{i, j}^{\mathrm{T}}\right)$ corresponds to the factor of sets $\mathrm{F}^{\mathrm{T}}\left(\Omega /\left\{k_{1}, k_{2}\right\}\right)$ for $\pi$-criterion $\pi\left(\Omega /\left\{k_{1}, k_{2}\right\}\right)$ and contains arcs that are laid «1» in $\mathrm{AM}_{12}$, defined by the rule:

$$
\begin{gathered}
\left\{U_{i j}^{T_{i j}}=\left\{<I, j>:\left(\forall i \neq j=\left\{1, N_{D}\right),(\forall l=\{1, M\}),\right.\right.\right. \\
\left.k_{l}\left(\omega_{i}\right) \geq k_{l}\left(\omega_{j}\right) \wedge \exists l_{0} \in\{1, M\} ; k_{l}\left(\omega_{i}\right)>k_{l}\left(\omega_{j}\right)\right\} .
\end{gathered}
$$

In the seventh step, a graphical interpretation of the transitive graph of $G^{T}\left(\mathrm{~W}, U^{T}{ }_{i j}\right)$ set is presented in accordance with $\mathrm{AM}_{12}$. Thus, the resulting multivariate multicriteria analysis presents solutions optimal in accordance with Pareto principles.

\section{Results}

The results of the seven steps of the multivariate multicriteria analysis for the selection of a method to implement digitalization in enterprises of the printing industry are presented below. In the first step, the characteristics of approaches are presented below, with the definition of the range of permissible values of characteristics for the selection of the desired approach (Table 4).

\begin{tabular}{|c|c|c|c|c|c|}
\hline \multirow{4}{*}{$\begin{array}{c}\text { Types } \\
\text { of approaches }\end{array}$} & \multicolumn{5}{|c|}{ General characteristics of approaches } \\
\hline & \multicolumn{3}{|c|}{ Conditions, limitations $\{C, L\}$} & \multicolumn{2}{|c|}{ Impact indicators $\{$ IF $\}$} \\
\hline & $\boldsymbol{v}$ & $m / l$ & $t^{*}$ & $\delta$ & $C-$ costs \\
\hline & $\geq$ & $\leq$ & $=$ & $\downarrow$ & $\downarrow$ \\
\hline Logistic & 50 & 2,1 & 360 & 2 & 2,4 \\
\hline Marketing & 20 & 3,5 & 360 & 1 & 2 \\
\hline Innovative & 70 & 1,8 & $180 \pm 5$ & 1,4 & 1,2 \\
\hline Technological & 25 & 4,4 & 360 & 3,2 & 1,8 \\
\hline Administrative & 100 & 1,8 & 360 & 3 & 1 \\
\hline Industrial & 15 & 3 & $180 \pm 5$ & 2,5 & 0,8 \\
\hline Competitive & 40 & 5 & $180 \pm 5$ & 4,6 & 0,8 \\
\hline Holding & 35 & 3,5 & $180 \pm 5$ & 2,8 & 0,4 \\
\hline
\end{tabular}

Table 4. Characteristics of approaches

Source: own elaboration. 
The analysis of above approaches' characteristics allowed us to determine the range of acceptable values of these characteristics and to define the IF set with the criteria required for the selection of the necessary approach.

Next, the output was evaluated by sorting these characteristics in the linearly increasing order. The variants of the design decision were indicated through $\omega_{i}$. Possible options $\Omega=\left\{\omega_{i}\right\},=\{1,8\}$ for the values in Table 4 are presented in Table 5 .

Table 5. General characteristics of approaches

\begin{tabular}{|c|c|c|c|c|c|c|}
\hline & & & & stic & proache & \\
\hline Tunge of & & & limita & & Impact $\mathrm{i}$ & $S\{I F\}$ \\
\hline & & $v$ & $m / l$ & $v$ & $m / l$ & $v$ \\
\hline & & $\geq$ & $\leq$ & $=$ & $\downarrow$ & $\downarrow$ \\
\hline Logistic & $\omega_{1}$ & 3 & 3 & 1 & 2 & 7 \\
\hline Marketing & $\omega_{2}$ & 7 & 5 & 2 & 1 & 6 \\
\hline Innovative & $\omega_{3}$ & 2 & 1 & 1 & 3 & 5 \\
\hline Technological & $\omega_{4}$ & 6 & 6 & 1 & 6 & 5 \\
\hline Administrative & $\omega_{5}$ & 1 & 2 & 1 & 5 & 4 \\
\hline Industrial & $\omega_{6}$ & 8 & 4 & 2 & 4 & 3 \\
\hline Competitive & $\omega_{7}$ & 4 & 7 & 2 & 7 & 2 \\
\hline Holding & $\omega_{8}$ & 5 & 5 & 2 & 5 & 1 \\
\hline
\end{tabular}

This is a solution to the problem of choosing acceptable for $\pi$ - criterion of variants of the associative ordering approaches in describing the factors of sets by associative matrices. In the fifth step, we created relational tables for the factor of sets by IF F $\mathrm{F}^{\mathrm{T}}\left(\Omega / k_{1}\right)$ and $\mathrm{F}^{\mathrm{T}}\left(\Omega / k_{2}\right)$ in the form of corresponding associative matrices (Tables 6 and 7) and their intersection according to rule (2) (Table 8). The resulting AM for the factor of sets $\mathrm{F}^{\mathrm{T}}\left(\Omega /\left\{k_{1}, k_{2}\right\}\right)$ on the basis of expression (2) is shown below. 
Table 6. The associative matrix $\mathbf{A} \mathbf{M}_{\mathbf{1}}$ for $\mathbf{F}^{\mathrm{T}}\left(\Omega / \boldsymbol{k}_{1}\right)$

\begin{tabular}{|c|c|c|c|c|c|c|c|}
\hline \multicolumn{10}{|c|}{$\mathbf{M}_{\mathbf{1}}$} \\
\hline $\boldsymbol{\omega}_{\mathbf{1}}$ & $\boldsymbol{\omega}_{\mathbf{2}}$ & $\boldsymbol{\omega}_{\mathbf{3}}$ & $\boldsymbol{\omega}_{\mathbf{4}}$ & $\boldsymbol{\omega}_{\mathbf{5}}$ & $\boldsymbol{\omega}_{\mathbf{6}}$ & $\boldsymbol{\omega}_{\mathbf{7}}$ & $\boldsymbol{\omega}_{\mathbf{8}}$ \\
\hline 0 & 0 & 0 & 1 & 0 & 0 & 1 & 1 \\
\hline 0 & 0 & 1 & 1 & 1 & 1 & 1 & 1 \\
\hline 0 & 0 & 0 & 0 & 0 & 0 & 1 & 0 \\
\hline 0 & 0 & 0 & 1 & 1 & 1 & 1 & 1 \\
\hline 0 & 0 & 0 & 0 & 0 & 0 & 0 & 0 \\
\hline 0 & 0 & 0 & 1 & 1 & 0 & 1 & 0 \\
\hline 0 & 0 & 0 & 1 & 1 & 0 & 1 & 1 \\
\hline 1 & 0 & 1 & 1 & 1 & 1 & 1 & 1 \\
\hline
\end{tabular}

Table 7. The associative matrix $\mathbf{A M}_{2}$ for $\mathbf{F}^{\mathrm{T}}\left(\Omega / \boldsymbol{k}_{\mathbf{2}}\right)$

\begin{tabular}{|c|c|c|c|c|c|c|c|c|}
\hline & \multicolumn{7}{|c|}{$A \mathbf{M}_{\mathbf{2}}$} \\
\hline$\omega_{\mathbf{1}}$ & 1 & 1 & 1 & 1 & 0 & 0 & 0 & 0 \\
\hline$\omega_{\mathbf{2}}$ & 0 & 0 & 0 & 0 & 0 & 0 & 0 & 0 \\
\hline$\omega_{3}$ & 1 & 1 & 1 & 0 & 0 & 0 & 0 & 0 \\
\hline$\omega_{\mathbf{4}}$ & 1 & 1 & 0 & 1 & 0 & 0 & 0 & 0 \\
\hline$\omega_{5}$ & 1 & 1 & 1 & 1 & 1 & 1 & 0 & 0 \\
\hline$\omega_{6}$ & 1 & 1 & 1 & 1 & 1 & 1 & 1 & 0 \\
\hline$\omega_{7}$ & 1 & 1 & 1 & 1 & 1 & 0 & 0 & 0 \\
\hline$\omega_{8}$ & 1 & 0 & 0 & 0 & 0 & 0 & 0 & 0 \\
\hline
\end{tabular}

Source: own elaboration.

Table 8. The associative matrix $\mathbf{A M}_{12}$ for $\mathbf{F}^{\mathrm{T}}\left(\Omega /\left\{\boldsymbol{k}_{1}, \boldsymbol{k}_{2}\right\}\right)$

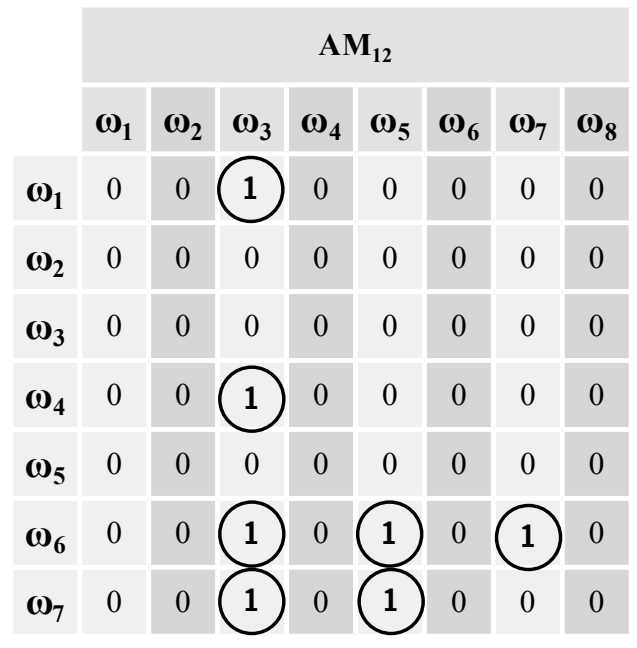

Source: own elaboration. 
In the next step, the graphical interpretation of the transitive graph $G^{T}\left(\Omega, U^{T} i j\right)$ was matched to the associative matrix $\mathrm{AM}_{12}$ (Figure 1).

Figure 1. Graphical interpretation $G^{T}\left(\Omega, U^{T}{ }_{i j}\right)$ for the factor of sets $\mathrm{F}^{\mathrm{T}}\left(\Omega /\left\{k_{1}, k_{2}\right\}\right)$

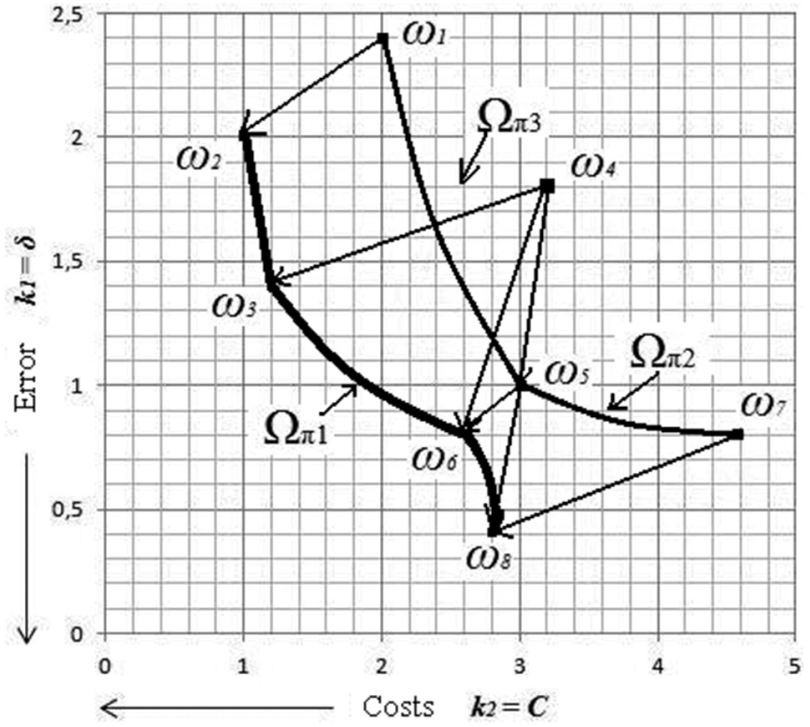

Source: own elaboration.

The analysis of the data presented in Figure 1 and Table 8 showed that the ultimate non-dominant approaches $\left\{\omega_{2}, \omega_{4}, \omega_{6}, \omega_{8}\right\}$ are optimal according to the Pareto principles. The number of arcs in $G^{T}\left(\Omega, U_{i j}^{T}\right)$ corresponds to the number " 1 " in $\mathrm{AM}_{12}$, presented in table $8\left(N_{\langle 1\rangle}=8\right)$, and furthermore, the number of $\pi$-layers, corresponds to the maximum number of elements of chains (non-transitive arcs) in the partial graph $G^{T}\left(\Omega, U_{i j}^{T}\right)$.

The SP gave the time range from $\mathrm{t} 1=0$ to $\mathrm{t} 2=360$ days. Therefore, the variants that satisfy the task set out in Table 3 are those that correspond to the value " 1 " for $t$, that is $\omega_{1}, \omega_{3}, \omega_{5}, \omega_{7}$. According to the Pareto principle, the best option is option $\omega_{5}$.

Options $\omega_{5}, \omega_{1}, \omega_{3}$ are acceptable according to the Pareto principle. Therefore, by introducing digitalization with different orientation vectors, one may increase the profitability of the enterprise. In order to choose one option, it is necessary to reduce alternatives by the strongest criterion, by introducing the priority of IF or setting additional conditions and restrictions. Based on the results of the current research, it is possible to create an algorithm for choosing an acceptable approach (Figure 2). 
Figure 2. An algorithm for choosing the approach to implement digitization

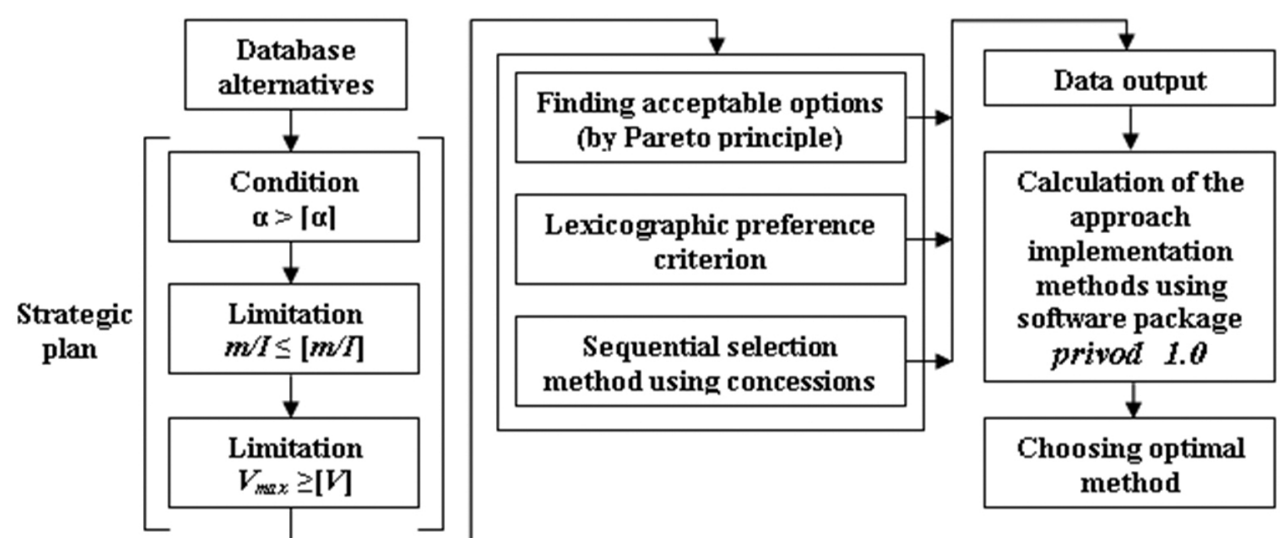

Source: own elaboration.

This article presents a method for the automated approach selection, which consists of several elements: a description of formalized assignment of conditions, limitations, and IF methods; the development of an algorithm to construct a partial order on W; the selection of p-layers and not worse options; deciding on the best option and making more precise calculations of the choice of approach.

The multivariate multicriteria analysis allowed us to determine the optimal method to implement digitalization in enterprises. As an example, this method was used for the analysis of the "Cartography" enterprise activities. The results show that the best approaches are logistics, innovation, and management. The estimation of the impact of optimal approaches on the efficiency of business process digitalization in "Cartography" enterprise is shown in Table 9.

Table 9. Results of multivariate multicriteria assessment of the efficiency of business processes digitalization in "Cartography" enterprise

\begin{tabular}{|l|c|c|c|}
\hline Enterprise & Approach & Logistic & Administrative \\
\hline $\begin{array}{l}\text { “Cartography" } \\
\text { enterprise }\end{array}$ & 3,451 & 7,593 & 10,784 \\
\hline
\end{tabular}

Source: own elaboration.

Based on the above, the "Cartography" enterprise should use an administrative approach to achieve the best impact on profitability. Personnel management processes are the 
first group of business processes that require modification in order to properly understand the changes in employees and managers. Among existing digital tools, it is important to distinguish the following:

- technologies with elements of artificial intelligence (the creation of virtual departments for personnel management, recruiter-bots; increasing the value of development of "soft" skills of employees such as leadership, emotional intelligence, teamwork, creativity, etc.);

- big data and advanced data analytics tools (forming multi-age teams of X, Y, and $\mathrm{Z}$ generation specialists;);

- the use of social media (reducing the threat of employee association or deformation of work behavior;);

- blockchain (staff relocation, remote employment, coworking; increased focus on cybersecurity);

- the application of robots: hardware or software (the integration of traditional professions with professions of information technologies);

- systems of continuous improvement e.g. Kaizen/Lean/Agile (the re-profiling of traditional personnel managers into coaches; the implementation of project management such as Agile, Lean, Scrum, and other; the development of programs such as "work-life balance," "talent management," "lifelong training," the introduction of HR analytics).

Since hardware, software, and staff costs are the basis of a company's overall costs, we would advise to reduce them by using artificial intelligence components in business processes.

Artificial Intelligence differs from conventional software by three major components: high-speed computing, large quantities of high-quality data, and advanced algorithms. With the help of algorithms, basic artificial intelligence technologies provide greater accuracy and stability of daily processes. Artificial intelligence technologies provide opportunities to improve all HR functions (Table 10).

Using modern tools of information transformation in personnel management process helps to minimize human factors and optimize time and costs. Moreover, it is important to consider the impact of digital transformation investments and strategic assets on the creation of a mechanism for the digitalization of enterprise personnel management processes with artificial intelligence. 


\section{Table 10. Key cases of the use of artificial intelligence in HR}

\section{Artificial intelligence in recruiting}

- Search for candidates;

- Evaluation of candidate;

- Interviews;

- Hire.

\section{Artificial intelligence in engaging employees}

- Intellectual surveys;

- Real-time feedback platforms;

- Awards and recognition;

- Personalized messaging and communication.

Source: own elaboration.

The mechanism of digitalization (Figure 3) must establish a clear interconnectedness of departments in an enterprise so as to ensure the unity of goals. The implementation of management as a process involves a certain order of performing various functions and preparing and making key decisions.

The basis for the digitalization mechanism of personnel management processes in an enterprise using artificial intelligence is described as a sequence of steps. Each step has its own levers and elements. The principles for constructing such a mechanism are:

- virtualization: the creation of virtual copies (models) of physical processes that receive information from sensors and devices, analyze and manage real processes, provide security measures, and only in the case of failure involve employees in the physical process.

- modularity: each module in the mechanism that has a certain functionality allows the system to flexibly adapt to changing requirements by replacing or expanding individual modules.

- education and continuous vocational education.

- decentralization: the integration of elements (computers, sensors, communication networks) that allows the embedded system to make its own decisions, in particular in matters of production planning and operational control.

- real-time interaction: the ability to interact with physical processes at appropriate pace.

- interoperability.

- service orientation: personnel management systems, equipped with Internet services, able to receive specific consumer requirements (Gudz, 2018; Gurenko and Gashutina, 2018).

The use of AI can be applied to such areas of HR processes as recruiting (hiring and adapting staff), training, development (by implementing modern training tools), analytics, and accounting. 
Figure 3. The mechanism of digitization in personnel management processes at the enterprise on the basis of introduction of artificial intelligence

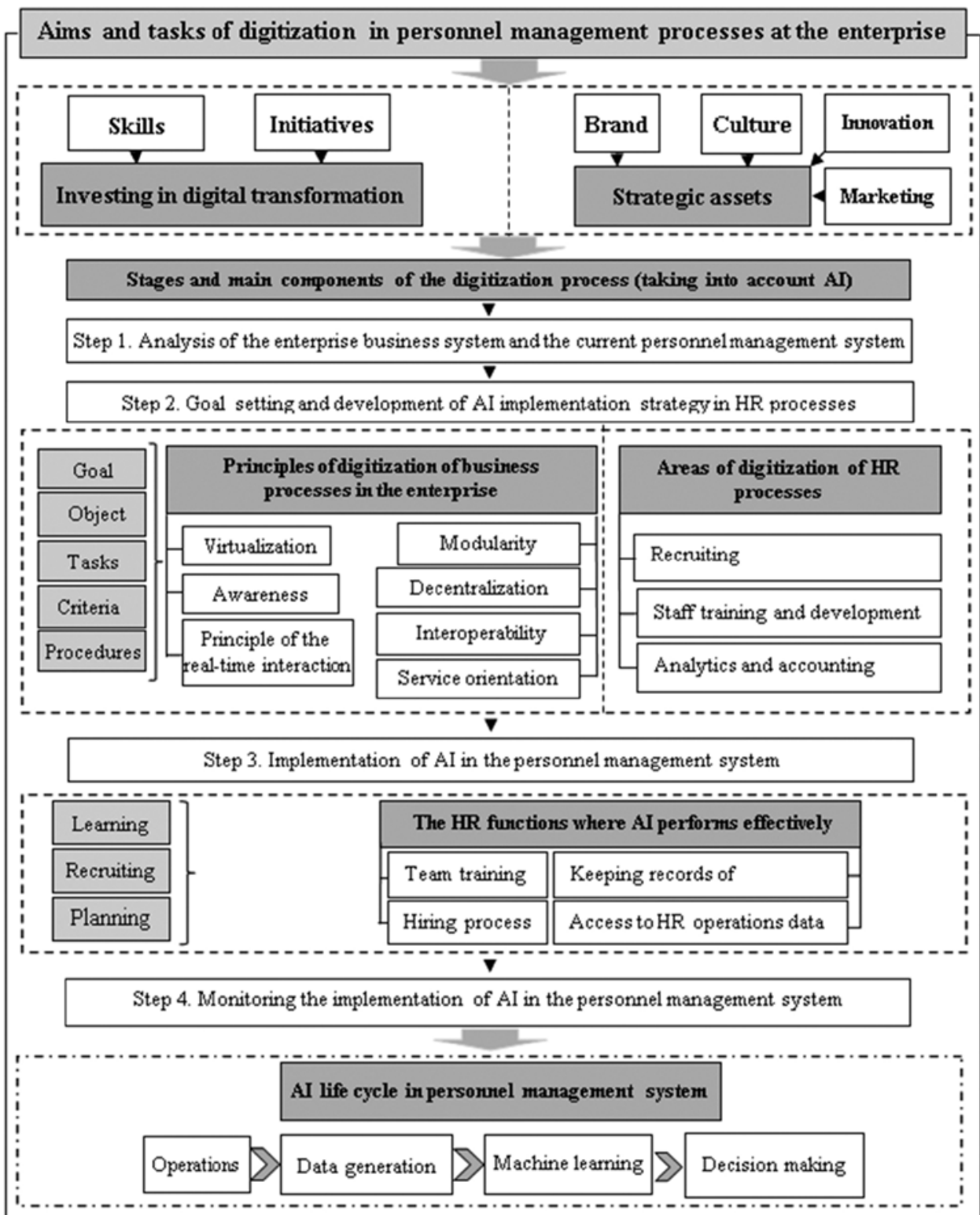

Socio-economic effect of the digitization of enterprise personnel management processes on the basis of artificial intelligence implementation

\begin{tabular}{|c|c|c|c|c|}
$\begin{array}{c}\text { Effective personnel } \\
\text { management system }\end{array}$ & $\begin{array}{c}\text { Human factor } \\
\text { minimization }\end{array}$ & $\begin{array}{c}\text { Growth of socio- } \\
\text { economic development }\end{array}$ & $\begin{array}{c}\text { Time and cost } \\
\text { optimization }\end{array}$ & $\begin{array}{c}\text { Increased } \\
\text { productivity }\end{array}$ \\
\hline
\end{tabular}

Source: own elaboration. 
HR functions in which AI performs efficiently are:

- review and adaptation of employee information: employees can access their personal information, organization information, available vacation days, vacation request status, and official HR service information.

- access to HR operations data: managers can access employee data about employee work history, team information, and performance ratings; conversational AI can also inform analytics and key performance metrics by querying chatbots.

- team training: team managers can plan digital learning opportunities for their teams based on skills gaps. AI is an opportunity for HR to automate repetitive, low-value tasks and focus on more strategic work.

- hiring process: cognitive solutions can help organizations to leverage multiple data sources, discover new ideas among the best candidate profiles, and improve the hiring process.

The first step analyzes the enterprise's business system. First, it evaluates the state of the business environment and the collection of information that forms the personnel management system. The mechanism of the digitalization of personnel management processes using AI is developed, considering the analysis of current personnel management system that highlights its strengths and weaknesses.

The second step sets goals alongside with the development of AI implementation strategy. When defining priority areas, elements of the personnel management system using AI - such as purpose, objectives, criteria, object, procedure - are considered and prescribed. The purpose is considered as the primary element of a management system that ensures effective enterprise performance. Objectives are set in such a way so that the main purpose will be achieved. Tasks are defined along with a set of measures that require implementation in the proposed area.

The third step introduces AI in the personnel management system, as the main direction of the system needs to be identified first. This includes training, recruiting, and planning, namely, creating virtual departments for personnel management and recruiter-bots, the personalization and emphasis on employees' soft skills development, e.g. leadership, emotional intelligence, teamwork, and creativity. To take a closer look at these processes, it is important to consider the life cycle of AI in HR when introducing AI in a defined direction. The life cycle consists of four phases: operations, data generation, machine learning, and decision-making. 
The operations phase includes the task of new employees hiring. Since the HR department performs many costly operations, reducing these costs will be beneficial for any enterprise. Therefore, using AI applications that help to reduce such costs is highly desirable. The following are the most common human resources operations with relevant workforce analytics tasks:

- recruiting: identifying potential candidates and their beliefs;

- selection: identifying the best candidates possible;

- adaptation: educating new employees to quickly become more productive;

- training: interventions that are meaningful to employees to improve their productivity;

- performance management: identifying performance indicators;

- promotion: determining who receives the promotion;

- resignation: the ability to predict who is likely to resign;

- employee benefits: the possibility to determine what benefits are more important for the payment of bonuses.

Each of these operations involves the execution of administrative tasks that affects the effectiveness of an organization. They produce huge amounts of data in the form of texts and records, and when these operations move into virtual space, their amount sharply decreases, which means that the operations are simplified.

The data generation phase involves the collection of data for the human resources information system, such as "digital exhausts."

The machine learning phase encompasses a wide range of techniques that can be used to write an algorithm for the execution of a specific task. In the business context, the widespread use of machine learning technologies is to "supervise" applications: creating an algorithm for machine learning, training, and application in business. Creating a machine learning algorithm determines the most appropriate metric to evaluate its accuracy. For recruiting, we can see the applicant's performance-related characteristics and use them to select candidates in the future.

The decision-making phase raises concerns about using machine learning techniques in daily operations. In the HR field, managers have more freedom to use empirical data from scientific information and other models. Managers can generate their own activity data, such as hiring interviews that they structure themselves. 
The key areas of AI influence in human capital management are leadership, coaching, performance management, workforce planning, virtual self-service assistants, the virtual provision of HR services.

In learning and development, AI enables learning platforms to reproduce the quality of successful platforms such as YouTube and Netflix to improve learning outcomes. Some of the key areas of impact include personalized learning avenues, e-learning analytics, and conversational interfaces.

The implementation of AI in HR delayed by financial barriers manifest in the lack of personnel, as it requires considerable expense and effort to find qualified personnel to serve and maintain AI. Other obstacles are privacy concerns (confidential information should be protected and allow limited accessibility), integration capabilities (limited data availability as HR trend toward Software as a Service), and limited licensing programs (as many products and services require concept validation).

The cost of using AI enables companies to minimize the time spent by HR professional on administrative tasks, reducing the burden on shared service centers by performing operations, responding to daily queries, and reducing bias in decision-making.

\section{Conclusion}

The results of the multivariate multicriteria analysis in approaches to implement digitalization in enterprises enabled us to build a formalized choice of the approach using the initial data and the unconditional Pareto principle, based on the linear ordering of impact indicator sets. Overall, this method for the implementation of digitalization has several advantages. It allows one to analyze many options and their further synthesis and a holistic view of optimal approaches to the implementation of digitalization. Moreover, it allows one to formulate criteria and build algorithms and programs for the automated selection of systematic approaches to implementation, but also to assess the level of influence of these approaches on enterprise activity. This will allow companies to choose the optimal approach which - through the optimization of business processes - will increase their profitability. Thus, the use of multivariate multicriteria analysis is appropriate and should be investigated further.

The results of the multivariate multicriteria analysis of approaches for the implementation of digitalization in industrial enterprises show that the logistic, innovative, and administrative approaches are the best. Out of these approaches, management assessment, 
which involves personnel management, has the greatest effectiveness in the introduction of digitalization. To introduce digitalization within the framework of this approach, we developed a mechanism of digitalization of personnel management processes based on the introduction of artificial intelligence with resource planning. The introduction of AI helps to minimize human factors, reduce costs, and increase sales and profits.

\section{$\underline{\text { References }}$}

Baker, M. (2014). Digital Transformation. Create Space Independent Publishing Platform.

Batrakova, T.I. and Kuznetsova, A.V. (2018). Features of the digital economy in Ukraine and in the world. Bulletin of Zaporizhzhya National University. Economic Sciences, 2, 84-89. http://nbuv.gov.ua/UJRN/Vznu_eco_2018_2_1.

Booz-Allen-Hamilton (2019). Innovation and Disruption. Real-world solution to cyber callengrs. http://www.boozallen.com/.

Bouwman, H., Nikou, Sh., J. Molina-Castillo, F. and de Reuver, M. (2018). The impact of digitalization on business models. Digital Policy, Regulation and Governance, 20(2), 105-124. https://doi.org/10.1108/DPRG-07-2017-0039.

Borysyak, O.V. (2018). Digitization in the enterprise personnel management system. Economic and Social Development of Ukraine in the 21st Century: National Vision and Challenges of Globalization: Coll. abstracts XV Jubilee International Scientific Conference of Young Scientists. Ternopil, March 29-30, 76-78.

Challenges for Competition Policy in a Digitalized Economy (2015). Brussels.

http://www.europarl.europa.eu/RegData/etudes/STUD/2015/542235/IPOL_STU(2015)542235_ EN.pdf.

Eder, D. and Buck, Ch. (2018). The Impact of Digitization on Business Models - A Systematic Literature Review. Research Center Finance and Information Management. 24 Americas Conference on Information Systems. New Orlean, August, 2-10.

https://www.fim-rc.de/Paperbibliothek/Veroeffentlicht/766/wi-766.pdf.

Digitization: how not to lose competitive advantage. http://www.management.com.ua/notes/digital-innovation.html.

Europa-2020. A European strategy for smart, sustainable and inclusive growth. http://ec.europa.eu/eu2020/pdf/COMPLET\%20EN\%20BARROSO\%20\%20\%20007\%20-\%20 Europe\%202020\%20-\%20EN\%20version.pdf.

Fomichev K., Go digital or die: Digitizing business as an inevitability. http://www.nand.ru/professional-information/and_library/20565/.

Gudz, O.E. (2018). The Digital Economy: Changing the Values and Landmarks of Enterprise Management. Economy. Management. Business, 2(24), 4-12. https://doi.org/10.31673/2415-8089.2019.030412.

Guseva, O.Y. and Legominova, S.V. (2018). Digitization as a tool for improving business processes, their optimization. Economy. Management. Business, 1(23), 33-39. http://journals.dut.edu.ua/index.php/emb/article/view/1812.

Gurenko, A.V. and Gashutina, A.E. (2018). Directions of management systems development in the conditions of business digitization in Ukraine. Economy and Society, 19, 739-745.

https://doi.org/10.32782/2524-0072/2018-19-113. 
Hammer, M. and Champy, J. (2009). Reengineering the Corporation: Manifesto for Business Revolution. New York. https://doi.org/10.1002/qre.4680100613.

Industry 4.0: The 2018 World Manufacturing Forum Report. https://www.worldmanufacturingforum. org/copia-di-wmf-report.

Kandirin, Yu V. and Koshelev, A.M. (2008). Automation of multicriteria structuring of alternatives based on their sequential ordering. Izv. VolgTU. Series "Actual problems of control, computer engineering and computer science in technical systems": intercollegiate. Sat. scientific Art./ VolgTU. Volgograd, 8(5), 31-36. https://www.elibrary.ru/item.asp?id=12793495.

Kandirin, Y.V. (2004). Methods and models of multicriteria choice of options in CAD. Textbook for universities. Publishing House of MEI.

Kolot, A. (2019). Work 4.0 as a model and platform for a new (digital) economy. Institutional Repository of Vadym Hetman Kyiv National Economic University, 13-28. https://ir.kneu.edu.ua/bitstream/handle/2018/31176/Sz_19-1.pdf?sequence=1.

Kolyadenko, S.V. (2016). The Digital Economy: Prerequisites and Stages of Formation in Ukraine and the World. Economy. Finances. Management: Topical Issues of Science and Practice, 6, 105-112.

Kraus, N.M., Goloborodko, O.P. and Kraus, K.M. (2018). Digital economy: trends and perspectives of the avant-garde nature of development. An Efficient Economy, 1.

http://ojs.dsau.dp. ua/index.php/efektyvna- ekonomika/article/view/997/862.

Law of Ukraine, On the Concept of the National Program of Informatization, No. 75/98 of 11.08.2013. http://zakon.rada.gov.ua/laws/show/75/98-\%D0\%B2\%D1\%80.

Lisova, R.M. (2019). The impact of digitization on the business model: stages and tools of digital transformation. Scientific Bulletin of Uzhgorod National University, 24(2), 114-119. https://dspace.uzhnu.edu.ua/jspui/handle/lib/25455.

Merkevicius, J., Davidaviciene, V., Raudeliuniene, J. and Buleca, J. (2015). Virtual organization: specifics of creation of personnel management system. Ekonomie a Management, 18(4), 200-211. https://doi.org/10.15240/tul/001/2015-4-014.

Mintz, O.Y. (2017). Methodology for modeling innovative intellectual decision-making systems in economy: monograph. Mariupol: State Technical University "PDTU”.

http://eir.pstu.edu/bitstream/handle/123456789/13748/\%D0\%9C\%D0\%B8\%D0\%BD\%D1\%86. pdf?sequence $=7$.

Nechepurenko, D.C. (2017). Features of introduction of world experience of using cloud technologies of erp-systems by the enterprises of machine-building industry. Scientific Bulletin of Kherson State University, 23(2), 83-85. http://nbuv.gov.ua/UJRN/Nvkhdu_en_2017_23\%282\%29__20.

Prodius, O.I. (2016). Theoretical and methodological foundations of business process reengineering. Economics, 6. https://economics.opu.ua/files/archive/2016/No6/79.pdf.

Rachinger, M., Rauter, R., Müller, Ch., Vorraber, W. and Schirgi, E. (2018). Digitalization and its influence on business model innovation. Journal of Manufacturing Technology Management, 20(7), 95-124. https://doi.org/10.1108/JMTM-01-2018-0020.

Rohrbeck, R., Thom, N. and Arnold, H. (2015). IT tools for foresight: The integrated insight and response system of Deutsche Telekom Innovation Laboratories. Technological Forecasting and Social Change, 97, 115-126. https://doi.org/10.1016/j.techfore.2013.09.015.

Schwab, K., The Fourth Industrial Revolution: what it means, how to respond. https://www.weforum. org/agenda/2016/01/the-fourth-industrial-revolution-what-it-means-and-how-to-respond.

Shalmo, D., Williams, Ch.A., Boardman, L. (2017). Digital transformation of bussines models - best practice, enablers and roadmap. International Journal of Innovation Management, 21(08), 1-17. https://doi.org/10.1142/S136391961740014X. 
Sokolova, G.B. (2018). Some aspects of digital economy development in Ukraine. Economic Bulletin of Donbass, 1(51), 92-96. http://nbuv.gov.ua/UJRN/ecvd_2018_1_17.

Tapscott, D. (1996). The Digital Economy: Promise and Peril in the Age of Networked Intelligence. New York, NY: McGraw-Hill. https://doi.org/10.10160099-1333(96)90098-1.

The Global Information Technology Report. Growth and Jobs in a Hyperconnected World. World Economic Forum and INSEAD. www.weforum.org/gitr

Tronko, V.V. (2015). The influence of ICT on the economic development of the country. An Efficient Economy, 4. http://www.economy.nayka.com.ua/?op=1\&z=3959.

Vishnevsky, O.S. (2016). Problems of strategic management of social - Ukraine's economic development, taking into account the processes of decentralization. Bulletin of the Economic Science of Ukraine, 1(30), 14-22. http://dspace.nbuv.gov.ua/handle/123456789/105890/.

Yip, A.W.H. and Bocken, N.M.P. (2018). Sustainable business model archetypes for the banking industry. Journal of Cleaner Production, 174, 150-160. https://doi.org/10.1016/j.jclepro.2017.10.190. 